\title{
Por uma esperança responsável: interpelações éticas e teológicas para uma Nova Práxis
}

\author{
For a Responsible hope: Ethical and Theological \\ interpellations for a New Praxis
}

\section{Cesar Kuzma*}

Pontifícia Universidade Católica do Rio de Janeiro (PUC-Rio), Rio de Janeiro, RJ, Brasil

\section{Resumo}

O trabalho de pesquisa que apresentamos tem a proposta de uma esperança responsável. Esta esperança pode ser compreendida na sua dimensão humana, naquilo que podemos esperar e que está ao nosso alcance, o que implica uma ação direta do ser humano na história, em vista de um futuro que se pode construir. No entanto, esta esperança também pode ser percebida teologicamente, sendo entendida como dom e como horizonte de resposta, o que possibilita ao ser humano um novo modo de agir e de se perceber diante de um futuro que o convida a algo novo, fazendo-o interagir com o contexto onde vive, em vista de um futuro que foi prometido e que alimenta esta

*CK: Doutor em Teologia, e-mail: ckuzma@puc-rio.br 
esperança na história, transformando-a em força e ação. Entendemos que há um caráter performativo que sustenta esta esperança em nível escatológico, o que resulta em uma atitude de responsabilidade para com o tempo presente, no exercício da solidariedade e no compromisso com o novo que se revela. Para atender a estes objetivos, este trabalho de pesquisa está dividido em três partes, partindo de uma discussão sobre o lugar da esperança, entendendo o conteúdo que a esperança cristã apresenta e o espaço que ela dispõe, hoje. Na sequência, o nosso enfoque estará nos fundamentos e nos desdobramentos que o tema propõe. E, por fim, a relação entre esperança e responsabilidade, na perspectiva de uma práxis que incida em uma nova postura ética e teológica.

Palavras-chave: Esperança. Responsabilidade. Ética. Ser Humano. Futuro.

\section{Abstract}

The research that we present has the proposal the responsible hope. This hope can be understood in its human dimension, in what we can expect and that is within our reach, that implies a direct action of the human being through history, looking in the direction of a future that can be built. However this hope can also be perceived theologically, being understood as a gift and as a horizon of response, which enables the human being to find a new way of acting and of perceiving himself before a future that invites him to something new, in which he can interact with the context where he lives, in view of a future that has been promised and that feeds this hope in history, transforming it into force and action. We understand that there is a performative character that sustains this hope on the eschatological level, which results in an attitude of responsibility towards the present time, though exercise of solidarity and in the commitment with the new that is revealed. In order to meet these objectives, this work of research is divided into three parts, starting with a discussion about where hope is placed, understanding the content that the Christian hope presents and the space that it has today. In the following, our focus will be on the fundamentals and developments that the theme proposes. And finally, the relationship between hope and responsibility, in the perspective of a praxis, that focuses on a new ethical and theological position.

Keywords: Hope. Responsibility. Ethics. Human Being. Future. 


\section{Introdução}

Para atender os objetivos do nosso trabalho de pesquisa e lançar um olhar em busca de uma esperança responsável, nós dividiremos o nosso trabalho em três partes. Na primeira parte faremos um questionamento sobre o lugar da esperança, tendo em vista os desafios e as questões que tocam esta problemática. Depois, seguiremos pelos fundamentos e desdobramentos que esta esperança oferece, a partir de interpelações e implicações que orientem a esperança a uma nova postura ética e teológica, em perspectiva de uma nova práxis. Na terceira e última parte, trataremos do tema em si, da esperança responsável, entendendo que esta é uma relação inerente à esperança, naquilo que ela oferece como atitude de resposta e de compromisso na fé. Seguiremos com uma pesquisa bibliográfica, utilizando autores que favoreçam esta discussão e proporcionem um olhar crítico para o tema e para a nossa realidade, onde repousamos a nossa abordagem.

\section{0 lugar da esperança}

Começamos a nossa reflexão com um questionamento direto: há espaço para a esperança, hoje? Esta pergunta, em tom genérico e aberto, traz consigo outros questionamentos que tendem a nos ajudar na problematização de nossa proposta, a fim de destacar na prática da esperança uma atitude de responsabilidade, entendida por nós como parte inerente do modo como se espera; algo próprio da fé que a garante e que a fundamenta. Tratamos aqui, especificamente, da esperança cristã, a qual tem uma base e desdobramento no evento Cristo, no encontro com o ressuscitado e crucificado. Assim, a projeção que se tem do ato de esperar é que vai definir o seu espaço e lugar, bem como a amplitude daquilo que compreendemos por esperança, naquilo que a antecede e no que se tornarão depois as suas implicações.

Hoje, ao se tentar caracterizar a esperança, pode-se buscar elementos diversos, da mesma forma como são diversos os objetos deste esperar; também dizendo, as muitas formas de esperança. Inicialmente, 
podemos compreender que aquilo que se espera vai estar definido pela finalidade do objeto [desta esperança], que vai nos trazer o como [o modo de esperar]. Seria como se perguntássemos: o que se espera [?], para quê se espera [?] e como se espera [?]. Teríamos aqui uma esperança mais do presente, do concreto da história, daquilo que é próprio do humano e de sua condição de ser, uma transcendência natural que busca a realização e a liberdade, ou seja, um novo estar. Ser e estar que se esperam novos. Piazza (2004), um autor que estaremos seguindo neste artigo, toca nestas questões e distingue a esperança em duas lógicas, a do possível e a do impossível, mas diz que ambas são marcadas pela imprevisibilidade e pela novidade. Características naturais de qualquer esperança. Se voltarmos ao questionamento que expusemos acima, às três perguntas, ele dirá que se trata de uma esperança como "lógica do possível", algo profundamente humano e natural, capaz de garantir a nossa existência, o nosso tempo e a nossa busca pelos limites da história, numa transcendência horizontal, naquilo que pode ser praticável para o ser humano e para o mundo (PIAZZA, 2004, p. 31). No entanto, para a esperança cristã, que ele trata como "lógica do impossível", existe a possibilidade de um dado novo que supera todo e qualquer limite da história, atingindo o ser humano e o mundo que o cerca, oferecendo a ele (e ao mundo) uma nova realidade que é inimaginável e inesperada (PIAZZA, 2004, p. 57), isto é, supera toda e qualquer intenção humana (inimaginável) e está acima do que previsivelmente e "logicamente" se pode esperar (inesperado). É dom, e a fonte deste dom é o próprio Deus, que age e revela um futuro para o ser humano, como um bem que somente em Cristo ressuscitado se pode esperar. O futuro vem como promessa aberta e esta condiciona o humano a um futuro também aberto, para o qual sai em missão, num agir que se compromete e que se faz responsável no tempo presente, tendo como referência o futuro que foi revelado e anunciado. É a tensão escatológica que alimenta todo esperar. Esta esperança não trará um fugir do mundo rumo a um futuro, mas vai impulsionar um agir transformador, em vista

Assinalamos a palavra "logicamente" porque esta apresentação que o autor [Piazza] faz sobre a esperança cristã, como lógica do impossivel, tem um tom paradoxal, já que a definição que se tem desta esperança e os fundamentos e horizontes que ela nos apresenta rompem com o que se pode definir "Iogicamente". 
deste futuro. Dito de outra forma, "aquilo que esperamos se integra numa fé que nos compromete à missão neste mundo, à missão da esperança cristã" (KUZMA, 2014, p. 62).

Mas é importante frisar que aqui se mudam as perguntas, pois o objeto desta esperança, aquilo que se espera, será definido não apenas no propósito do "para que se espera" (na finalidade), mas também em vista do "por que" e "por quem se espera", e estes "por que" e "por quem" fundamentam e definem a razão e o destino desta esperança. A diferença vai estar na força que nutre cada esperança e no destino que a aguarda, a sua realização. Há uma razão teológica neste ato porque Cristo é a fonte desta esperança (cf. $\mathrm{Cl} 1,27)$, sobretudo pela antecipação que nos é oferecida pelo evento de sua ressurreição que avança no tempo e nos toca no íntimo de nossa existência, junto aos dramas e tramas da história, provocandonos a agir e a caminhar na sua direção, rumo a um futuro novo que nos foi prometido e que só pode ser garantido por esta esperança. É o que assegura Pannenberg (2009): "No caminho de sua história no tempo, as coisas e as pessoas existem somente pela antecipação daquilo que elas serão à luz de seu último futuro, do advento de Deus" (p. 698). E esta antecipação, do modo como é recebida e acolhida na fé, faz brotar uma esperança que, de dom, transforma-se em força e, com isso, impele o ser humano a agir e a transformar as estruturas do presente, fazendo eco ao futuro, mesmo contra todas as demais esperanças (cf. Rm 4,18) e frustrações que o tempo pode trazer. Diante deste futuro e da esperança que nasce a partir dele, o ser humano é chamado a decidir, a tomar posição; e o horizonte último, que é marcado pela esperança, dá consistência à forma de esperar, a uma condição de responsabilidade para com a realidade (PIAZZA, 2004, p. 65).

Todavia, se nós não nos detivermos na especificidade desta esperança, vista aqui no seu sentido cristão, a razão que a fundamenta e o destino que ela busca [espera] esvazia-se de conteúdo. Faz-se necessário, pois, perguntar sobre o lugar da esperança, se ela encontra espaço na atual sociedade e de que maneira o ato de esperar formaliza uma expectativa nova para o ser humano de hoje, seja em âmbito de religiosidade seja em âmbito de humanidade/sociedade, onde ele está inserido e responde contextualmente a sua fé. O lugar da esperança vai determinar o tempo desta espera e o modo como ela se dá, mas também a tensão que ela 
suporta, já que o fundamento da esperança é escatológico, marcado por uma antecipação do futuro que se faz sentir no presente da história, nos conflitos e contradições, nas alegrias e nas lutas diárias, em tudo aquilo que nos dá razão de esperar, na promessa de algo novo.

Por esta razão, faz-se relevante trazer para esta nossa reflexão algumas perguntas e questionamentos que nos possibilitem discutir sobre o lugar da esperança hoje e se ela ainda encontra espaço na atualidade, diante de todos os desafios que temos e de todas as urgências que nos chegam a todo tempo. Perguntamos: é possível esperar algo novo? É possível esperar algo novo em nível de sociedade e de realização humana, mas também em âmbito de fé? E como se dá a nossa posição diante daquilo que se espera, qual é a nossa atitude? O que temos a oferecer, em decorrência do que estamos esperando e já experimentamos na fé, uma fé que é na sua essência esperança? E mais, é possível — ainda - continuar a esperar, a ter esperança, mesmo contra toda esperança? Deixemo-nos questionar.

A realidade atual e as diversas situações que nos confrontam no cotidiano parecem não ceder espaço à esperança ou a qualquer expectativa de um futuro aberto, ou, quando fazem, trazem outro modo de esperar. Se a esperança não encontra um lugar ou se ela não se faz perceptível, a reação de vazio impera e causa certo desiquilíbrio em tudo o que se pode encontrar, também no modo de ser e se portar, pois a vida parece não ter sentido e aquilo que se pode ver é basicamente aquilo que se pode olhar de perto e que é possível pegar com as mãos; diminuem-se as expectativas e se perdem as razões. Se nada está à nossa frente e se não há algo a se esperar ou buscar, então o ser humano volta-se apenas para si, fecha-se em si mesmo, tendo frustrada toda a sua condição de presente. Temos aí o contrário da esperança, o desespero (a des-esperança), que reproduz a incapacidade do ser humano de agir em prol de algo para além de si mesmo ou ainda a carência de sentir a própria vida; pois já não há futuro, porque não pode esperar, tampouco há presente, porque as forças se esgotam e já não pode viver. O que se tem são imagens de algo que poderia vir a ser, mas sem qualquer projeção, inquietude ou garantia de que irá se tornar real; ou de algo que passou, mas que não corresponde à realidade vivida.

Outra situação que se faz sentir hoje e nos faz questionar sobre o lugar da esperança vem das dificuldades de se projetar um futuro para 
o nosso contexto, em que se possa cessar a violência e todas as formas de discriminação e preconceito, para que enfim se possa reinar a paz e a justiça, num mundo que faça prevalecer a igualdade e onde o direito dos mais fracos, sobretudo dos pobres, se torne um imperativo ético sem distorções, mas que garanta a sua integralidade, na centralidade da pessoa (cf. GS 12). É preciso perguntar, como faz Gutiérrez (2003), onde dormirão os pobres, pois a pobreza possui muitos rostos e reúne em si todo o limite humano diante das realidades. Para ele, pobreza significa morte (GUTIÉRREZ, 2000, p. 20); e esta morte acusa um tempo-limite que nos obriga a uma nova atitude de esperança, atenta e comprometida com esta realidade: uma esperança em ato.

Todas estas dificuldades do tempo presente constituem-se em obstáculos para a esperança, pontos de desafios que vão exigir uma nova postura capaz de despertar a esperança de um modo crítico e criativo. Dentro desta condição e em meio as dificuldades, a esperança é projetada para um tempo e espaço distantes, gerando frustração e descrença. Por certo, é um dado que nos questiona e que se faz bastante presente na atualidade, marcada por um espaço de pós-modernidade ou de uma pós-sociedade (GIDDENS, 2002) que se demonstra fracassada e frágil em vários horizontes, fazendo-se, também, muitas vezes, líquida (BAUMAN, 2001), e em outras, sem sentido (BOFF, 2014), e, em muitas, desigual (FRANCISCO, 2013, n. 52-60).

Faz-se urgente, então, perguntar sobre o lugar da esperança, hoje, já que ela não se traduz num abandonar-se a um futuro incerto, muito menos num debruçar-se num presente contínuo. Muito além disso, esta esperança que vem a nós como dom de Deus torna-se força por se fazer pulsar através de um futuro novo, que nos é antecipado pelo encontro do ressuscitado na história, ao nos convidar à práxis do seu Reino e ao seguimento de sua proposta, que se traduz em gestos concretos e em opções bem determinadas (cf. Lc 4,18-19). E mesmo que esta esperança descortine algo de inimaginável e inesperado, superando para algo novo, ela se permite acontecer nas muitas esperanças do presente, em práticas possíveis e de lutas diárias, de encontros marcados, que servem como degraus e diálogo com aquilo que, em graça, nos é dado a esperar, além de nós mesmos, pois "há no coração humano uma esperança para além do que se espera" (RIBEIRO, 2007, p. 151). Este futuro anunciado nos 
alimenta no presente, condicionando o nosso agir e nos fazendo solidários com o mundo e com as pessoas que nos cercam. Esta solidariedade terá incidência numa prática responsável que é assumida na fé.

Viver com esperança neste contexto é estar disposto e decidido a dar razões daquilo que crê e, ao mesmo tempo, estar aberto para acolher o novo que chega até nós. É ter clareza de que o mundo de hoje se mostra bastante plural, o que vai fazer com que tenhamos a capacidade de se despir de preconceitos, mas que possamos também nos abrir para entender a realidade. Neste mundo plural, a desigualdade social, a violência, a miséria, a pobreza, a morte de inocentes, a injustiça ainda são marcas que devem ser superadas; e a esperança cristã e a sua missão devem se fundar nisso (KUZMA, 2014, p. 70-71).

\section{Fundamentos e desdobramentos desta esperança, em vista de uma práxis correspondente}

Seguimos o nosso raciocínio teológico pela mesma linha do que expusemos acima, partindo, agora, para uma caracterização desta esperança na base de seus fundamentos e possíveis desdobramentos que possam surgir, em vista de uma práxis correspondente.

Piazza, além do que define como possível e impossível para a esperança, traz também outra reflexão que nos parece ser útil aqui, ao distinguir "a esperança de" e a "esperança em" (PIAZZA, 2004, p. 73). O que ele compreende como "esperança de" está marcado pelo horizonte do possível e daquilo que se pode esperar e almejar, tendo como força a vontade humana e o seu desejo de realizar. Valoriza-se aí toda a racionalidade humana e os avanços que conquistamos em meio à sociedade. $\mathrm{O}$ fato de termos o que esperar, de modo prático, coloca a humanidade em movimento, pois se aspira algo além do que se pode ver e tocar, e isso tampouco é uma ilusão, mas é uma condição necessária e presente na ótica do ser. Esta noção de esperança também traz o seu enfrentamento, pois ela só existe mediante uma falta ou a partir de um sentimento de concretude que o tempo presente parece deixar ausente. Projeta-se, então, uma esperança que busca partir para conquistar o futuro e dar um novo significado para o presente, criando espaços, abrindo 
caminhos e sendo resistência - e mesmo resiliência - em meio à realidade e pontos de conflito, muitas vezes na ótica do direito, em aspectos sociais e da dignidade humana. Enfatizamos que não há problema nesta esperança e ela é intrínseca ao que se pode caracterizar como desejo humano, que tem na transcendência, na busca de realização, uma atitude natural. Dizemos que ela se faz necessária e, seguramente, as implicações éticas deste esperar são valiosas e devem ser aproveitadas em suas intenções, pois trazem ressonância com o que buscamos e queremos apresentar como responsável.

O fato de ele desenvolver e chamar a atenção para uma "esperança em" é que ambas as esperanças se supõem e se implicam mutuamente (PIAZZA, 2004, p. 74). A “esperança em" oferece algo de novo àquilo que se espera na "esperança de", evitando que esta fique circunscrita à pontualidade histórica das coisas que são desejadas. Do mesmo modo, a "esperança de" oferece espaço de realização para a "esperança em", qualificando o conteúdo desta espera que tem base e estrutura no mistério Pascal, no evento Cristo, ressuscitado-crucificado. Se na primeira subsiste a razão da incerteza, na segunda se aprofunda o horizonte da fé, que, mesmo marcada pela tensão da certeza-incerteza, dá conteúdo e substância a tudo o que se espera. Aquilo que posso esperar ganha um novo sentido naquilo que me é dado a esperar. É o novo, é o que pode ser oferecido ao ser humano concreto e, a partir dele, a toda a história, com razão e suporte de existência, na proposta de um futuro que não se deixa estacionar no presente, mas que em nenhum momento se transforma em fuga da realidade, mas em força e ação que buscam agir e transformar tudo o que existe.

Seguramente, esta noção de esperança tende a encorajar aquele que vive deste esperar, reproduzindo nele sementes de um tempo novo. Nas palavras do autor, a "esperança em" torna-se "experiência, partilha, participação, imitação e seguimento de uma pessoa, Cristo, o qual, com a própria vida e com o mistério de sua paixão, morte e ressurreição, deu novo sentido e forma a tantas esperanças que têm sua raiz no coração do homem e do cosmo" (PIAZZA, 2004, p. 80). Trata-se de uma esperança produzida por um encontro e este encontro nos fortalece no esperar, dá-nos algo e, ao mesmo tempo, nos impele a construir e a se projetar em esperança, de modo crítico, aberto, criativo e solidário. 
Moltmann (2005), conhecido como teólogo da esperança, mesmo em outras palavras, também traz esta reflexão, dizendo que o que caracteriza a esperança cristã é a sua raiz e fonte em Cristo, que como ressuscitado-crucificado abre um vasto horizonte em esperança (p. 415). Há nesta espera, segundo ele, uma atitude criativa e a mesma se faz crítica em relação à história (p. 416), pois ela sobrevive em meio a uma tensão do futuro prometido e o presente ainda não realizado, que encontra na cruz do crucificado uma forma de protesto e de esperança. Acreditamos que, tendo por base a teologia de Moltmann, é possível oferecer uma reflexão sobre o evento da cruz e a condição de esperança que este evento desperta. E este é um ponto que queremos tratar como desdobramento desta esperança, pois sendo ela uma esperança que se antecipa no presente e traz enfrentamento, luta e contradição com a história, não podemos nos esquivar do evento determinante da cruz, quando esta esperança é questionada e parece perder a sua força. Vemos a cruz de Cristo e as muitas cruzes de hoje. Ouvimos o grito do Cristo na cruz e ouvimos os muitos gritos dos crucificados de hoje. Vemos a esperança solidária que se manifesta em meio à morte e percebemos um renascer de esperança que nos interpela e nos provoca a uma atitude, hoje, num modo de agir e de se manifestar, permitindo-se interrogar pelas condições do tempo presente.

Obviamente que, se estivermos olhando apenas para a cruz e vendo nela o fim de tudo aquilo que esperamos, esta experiência torna-se frustrante e limitada. É onde se encerram muitas das nossas lutas e expectativas mundanas, muito bem caracterizadas pela "esperança de", dita por Piazza, atenta às possibilidades que dominam o tempo e o espaço e limitam todo o nosso esperar. No entanto, se conseguirmos olhar para além da cruz e o que ela carrega de conteúdo e significado, estamos nos abrindo para uma nova experiência, daquilo que a cruz nos oferece como seu destino (a ressurreição) e como esta novidade interage e ilumina todo o presente e toda a história: a "esperança em". Não se quer com isso valorizar o sofrimento ou mesmo a cruz, mas fazer valer a causa daquele (Cristo) que nela foi crucificado e que pela fé nos possibilita a experiência da ressurreição. Faz-se necessário se permitir interpelar por este mistério e, a partir dele, e nele, perceber os desdobramentos de nossa esperança, o que ela implica e o que ela responde. Há um olhar solidário na cruz que interroga a todos. Há um silencio na cruz que 
nos faz pensar. Há uma pergunta não respondida que somente no horizonte da fé é que se pode responder, o que faz cessar toda vontade humana, vivida nas muitas esperanças que se encerram na cruz, mas que ela, pelo mistério que nos revela, pelo aspecto novo, faz abrir outro espaço de tempo, em que a força do ressuscitado transforma e reabilita o que esperamos, antecipando-se na história, marcando a mesma, impulsionando-nos a ter a mesma atitude de compaixão e de solidariedade. Ao sermos marcados por este evento (que é implícito à fé), nós nos tornamos também responsáveis pela sua causa, e isso marca tudo aquilo que nós esperamos.

Dentro da teologia de Moltmann, desenvolvida na sua obra O Deus Crucificado (2011) a cruz é um sinal de abandono, mas também um sinal de protesto e, se pode dizer, de modo "invertido", ao reverso, é um sinal de justiça que nos interpela, ela nos questiona. Isto é, a cruz de Cristo nos interpela em nossa posição e atitude diante da justiça e das injustiças que presenciamos, e que nos cercam; ela questiona o nosso estado de ser e o local onde estamos, questiona por quem lutamos e com quem estamos em cada tempo e lugar. Dentro do que estamos tratando aqui nesta reflexão, dizemos que ela nos coloca numa esperança responsável, pois passamos a responder pela fé que nos compromete e nos impele a uma nova atitude. Por isso dizemos que ela é um sinal "invertido" de justiça, ao reverso, pois o crucificado foi em seu tempo e ainda é hoje, em sua reprodução histórica e cotidiana, uma vítima injustiçada de uma religião e sociedade que matam e exploram (em cada tempo) e que pretendem ser assim referências e fim em si mesmas. No entanto, ao assumi-la como critério e consequência de uma vida livre, Jesus se colocou de modo solidário ao lado dos injustiçados da história e ofereceu a eles um gesto de vida que transcende a própria cruz e o destino que ela conduz, já que aponta a um futuro diferente, a uma liberdade e atitude de protesto, de entrega, e, em última razão, de esperança. Dizemos que ele respondeu à sua causa, e o fez com a própria vida.

O gesto de Jesus no caminho da cruz e a experiência de fé que brota a partir dela não terminam na morte, mas espelham a morte como uma entrega total que se eleva a um horizonte escatológico novo e que culmina com a ressurreição. Este sim é o grande sinal que enche a cruz de conteúdo escatológico e de esperança; e ilumina o que antecedeu a ela (as opções e caminhos) e o que a transcende, que é o culminar de toda a 
esperança e o superar das desesperanças. E aqui, em um novo tempo que se inaugura a partir deste tempo, aquele que era injustiçado encontra a sua justiça, aquele que estava perdido agora é encontrado, e aquele que estava morto agora vive (cf. Lc 15,32). O Cristo crucificado e injustiçado se lança solidário e solitário, em uma atitude de entrega que não permite mais a ninguém uma vida solitária (KUZMA, 2014, p. 178), mas vida em comunhão e de sentido (MOLTMANN, 2011, p. 81). Apontamos, assim, que Deus "inverte" a posição da justiça, fazendo-a crescer a partir da vítima e das vítimas, pelo reverso da história, quando a contradição oferece um novo rumo e um novo modo de estar e de ser. Esta é uma reflexão muito bem desenvolvida por Sobrino (1994; 2000), que, ao recepcionar e interpretar a teologia de Moltmann na América Latina, exprime no clamor das vítimas uma autêntica interlocução.

A intolerância da cruz e a experiência que acolhemos do crucificado nos coloca de modo intolerante contra a injustiça, contra o descaso humano e a falta de sensibilidade; ela nos obriga a tomar partido pelos últimos da história, pelos pobres, vulneráveis, perseguidos e nos coloca junto a todas as vítimas de nosso tempo. A reflexão que se faz sobre a cruz e o despertar de uma esperança crítica que ela provoca não permitem uma postura fechada, isolada. Ao contrário exigem uma postura e teologia abertas, em diálogo e em confronto com as grandes causas da humanidade/sociedade, num compromisso gerador de um ethos correspondente, de uma práxis. Eis o que pretendemos desdobrar no entendimento da esperança cristã, que dentro da história, como vimos, encontra um espaço vital. No percurso que a teologia de Moltmann nos oferece, a cruz nos faz perceber "a dor de Deus" (MOLTMANN, 2011, p. 296-313), pois cremos em um Deus que não nos observa de longe, mas que acompanha a história, que ouve o seu clamor, o seu grito e se deixou tocar por ela, num pathos divino que nos incide a um pathos também humano, envolvendo-nos e nos sensibilizando com a sua kénosis; uma kénosis total e absoluta, a ponto de o Deus cristão ter se feito morte, chegando à fronteira e ao limite da história.

Voltando aqui ao argumento de Piazza com o qual iniciamos a nossa reflexão, dizemos que este é o lugar, o espaço, onde as esperanças do possível se realizam na esperança do impossível, em uma possibilidade aberta pelo próprio Deus. Isso, seguramente, interpela a nossa posição 
e condição, obrigando-nos a uma nova atitude, a uma nova práxis, em resposta ao que vemos e percebemos de Deus na história. Como já dissemos acima, todo este evento nos abre novas possibilidades para um novo futuro, para um novo tempo, mesmo diante de uma insistente e evidente tensão: "a busca de uma incidência efetiva da esperança na história e para a história" (PIAZZA, 2004, p. 65), onde o eterno toma parte no tempo e nos impele a uma reação, uma reação de esperança, uma esperança responsável.

\section{Esperança e responsabilidade}

$\mathrm{Na}$ intenção de relacionar esperança e responsabilidade e, ainda, como desfecho denossa reflexão, apresentamos aqui o caráter performativo da esperança. Entendemos, como vimos acima, que esta esperança nasce de uma experiência com o ressuscitado, a partir de um encontro, de onde respondemos na fé e buscamos realizar o futuro desta esperança. Isso se faz no diálogo e no enfrentamento com as causas humanas, com as urgências do nosso tempo e no confrontar da história. Junto à fé, ela será uma resposta ao chamado e aquilo que nos é revelado e oferecido como futuro, ou seja, a esperança assume um tom de compromisso e de obediência com o que é apresentado, trazendo a garantia, num caminhar e num impulso novo, logo responsável. O espaço que se pode criar com esta esperança oferece um novo sentido às realidades do presente, em vista do que se pode esperar do encontro com o ressuscitado, que avança com o seu futuro e nos antecipa a promessa do seu Reino. Nada é estranho à esperança, diz Piazza, que ao relacionar as características da esperança e aquilo a que esta responde - e que assume - insiste que a mesma esperança "ensina a avaliar com espírito crítico as condições do presente em uma perspectiva de conclusão e de cumprimento, de modo inesperado e inimaginável" (PIAZZA, 2004, p. 66).

É a razão pela qual a esperança pode ser vista como um princípio (BLOCH, 2005), pois a mesma tem o poder de agir na história, já que se faz sentir no tempo e ultrapassa as fronteiras do que meramente pode-se esperar. Ela implica um futuro. Sempre há espaço para o novo, para o que pode nos surpreender. Muito embora, a noção de esperança que Ernst Bloch 
nos apresenta em seu Princípio Esperança manifesta-se diante do possível; é o concreto da história que exige e espera a ação humana, podendo realizarse ou perder-se diante do desconhecido e/ou do que é incerto; ela é utópica. $\mathrm{Na}$ ocasião [nos anos de 1960], Moltmann sente-se tocado pelo horizonte aberto por Bloch e traz esta percepção como um desafio para o contexto cristão, onde este futuro desconhecido passa a ser conhecido no âmbito da fé e o que é incerto transforma-se em força de busca no seguimento de Cristo, ressuscitado-crucificado. Moltmann pega a força da esperança apresentada por Bloch e articula a esperança garantida na fé, fortalecida pela compreensão de promessa, a qual abre para o presente um novo horizonte, um futuro novo. Num linguajar moltmaniano, num "espaço vasto" (Weiter Raum: MOLTMANN, 2006). É o que encontramos na Teologia da Esperança, onde através de um diálogo crítico, Moltmann acolhe o start da esperança de Bloch, traduzindo-o e recepcionando-o numa dimensão maior, pois mesmo não sendo utópica (como posição última), a esperança cristã se alimenta das utopias para poder se expressar e realizar-se no presente, trazendo para si, e em si, a concretização de todo um processo da história. Moltmann diz que ela rompe com os horizontes utopicamente fechados, mas caminha — junto — nos horizontes utopicamente abertos, reconhecendo e mostrando o necessário. Desta forma, "a esperança escatológica se torna força impulsionadora da história para a criação de utopias do amor ao ser humano sofredor e seu mundo malogrado, ao encontro do futuro desconhecido, mas prometido de Deus" (MOLTMANN, 2005, p. 453).

Também, contrapondo-se ao Princípio Esperança de Bloch, temos o Princípio Responsabilidade de Hans Jonas. Trata-se de uma referência do tema em questão (responsabilidade) e que merece um acurado estudo e favorece um diálogo construtivo para com a teologia, diante dos desafios do mundo atual, onde o esperar e o parar parecem se confundir. Jonas não parte de uma noção teológica da esperança, mas sim de um instrumental filosófico e de uma constatação contemporânea, diante dos avanços e desafios trazidos pela tecnologia e pelo mundo moderno. Ao se contrapor ao Princípio Esperança de Bloch, ele argumenta que a condição para fazer algo, e para esperar, pode se tratar mais de uma confiança em fazer do que geralmente esperança. Diante do imprevisível, o medo pode surgir e abafar a espera pela incerteza, não sendo possível, pois, conseguir ou realizar aquilo que se desejou (JONAS, 2006, p. 351). Neste caso, para ele, 
devido ao caráter incerto da esperança, a ação responsável não se deixa deter por isso, assumindo a responsabilidade pelo presente e pelo futuro (JONAS, 2006, p. 351-352).

Todavia, este argumento que é colocado cabe muito bem no que se compreende por uma "esperança de", do que se pode projetar como "possível” e que se faz sensível na história e nas interpelações humanas. O que se propõe como esperança cristã está acima disso, pois não se espera simplesmente a partir do humano e da história, mas passa-se a esperar a partir de um futuro que é revelado e que se torna acolhido na fé. Entramos aí em outra categoria, de fundo teológico, porém, ela é capaz de oferecer algo e, ao mesmo tempo, assumir todo o caráter utópico do que Bloch argumenta e todo aparato da responsabilidade que Jonas propõe. São argumentos importantes e necessários e ambos possuem uma função importante: fazem com que a teologia e o olhar ético que estamos propondo estacionem-se em situações concretas, em perguntas existenciais, estejam abertos ao diálogo e àquilo que o humano pode almejar, buscar, esperar. Se acima pensamos em implicações éticas e teológicas, estas não podem prescindir destas interpelações, bem como de outras (e de outros autores) que nos fazem pensar e questionar a história, as relações, os costumes e o tempo; e, junto a isso, nos deixamos tocar pela esperança cristã que nos acolhe na fragilidade da existência, assumindo todo o nosso ser e toda a nossa história, convidando-nos a um agir com ele, nele, e para ele. Somente em Cristo é que o ser humano encontra a sua plena realização (cf. GS 22), e é ele aquele que se deve esperar, é a porta do futuro, e ela se abre a nós e se achega a nós, provocando-nos a um novo modo de agir e estar.

Por esta razão, se faz verdadeira e é provocativa a intenção de uma esperança responsável, que como dissemos acima, é inerente à condição da própria esperança. Trata-se de uma esperança que se orienta na fé e que se realiza no amor, que é a consumação do futuro que é prometido e é a única força capaz de não frustrar o espaço e tempo presente. Esta esperança "requer uma disponibilidade efetiva em relação a tudo aquilo que é oferecido como dom e a tudo quanto o amor eticamente espera" (PIAZZA, 2004, p. 67). Ela é "memória de futuro" (PIAZZA, 2004, p. 67), articulando o tempo e o seu verdadeiro sentido, sendo obediência no futuro e solidariedade no presente. Ela faz pulsar e resistir na insistência 
de que há algo que nos espera e que, por sua vez, é a razão de todo o nosso esperar. Deste modo, esta esperança responsável será percebida e exigida numa ação solidária, num compromisso autêntico com as causas que reclamam a justiça e o direito, num olhar de misericórdia e de compreensão frente aos limites do humano e da história. A responsabilidade exige um posicionamento ético da esperança (MOLTMANN, 2012); e, diante disso, apenas a justiça é capaz de criar um futuro novo (MOLTMANN, 1990).

Para fechar e avançar no que queremos propor como esperança responsável, dizemos que estamos diante de novas questões, verdadeiras interpelações que trazem implicações éticas e teológicas para uma nova práxis. Dentro do conceito de esperança, percebemos que há um salto qualitativo daquilo que posso esperar para aquilo que me é dado a esperar, sendo que a segunda incide diretamente na primeira, e a primeira é chamada a realizar-se na segunda. No entanto, visando a proposta de nosso trabalho, outro salto se faz necessário, pois se faz urgente a pergunta: com quem devo esperar aquilo que me é dado a esperar? Se a esperança se faz responsável, ela também se faz coletiva. Aquilo que se espera, se espera com todos, em todos e por todos.

\section{Considerações finais}

Quando acima nós nos perguntamos sobre o lugar da esperança, muitas destas interpelações que o trabalho desencadeou no seu final, bem como as diversas provocações trazidas pelos autores utilizados se fizeram presentes; e mesmo nas entrelinhas, é possível reler e perceber algumas indagações. Hoje, a realidade na qual estamos inseridos é diversa, plural e nos questiona enquanto humanos e enquanto homens e mulheres de fé. $\mathrm{O}$ mesmo se pode dizer quando tratamos dos fundamentos e desdobramentos da esperança, naquilo que envolve o evento Cristo e o que a sua ressurreição e cruz têm a nos dizer, hoje. É por onde caminhamos para trazer a ideia de uma esperança responsável. Acreditamos que as interpelações propostas pelas filosofias de Bloch e Jonas e também pelas teologias de Moltmann e Piazza nos favorecem a discussão. O mesmo se pode dizer dos outros autores utilizados. Filosoficamente, as indagações nos questionam no agir da 
esperança e no que podemos esperar, para qual horizonte. Teologicamente, podemos abrir-nos a um mistério maior, que não nos deixa sós, nem mesmo nos permite fugir do que nos reclama, mas leva-nos a um compromisso e a uma atitude de resposta; num responder coerente de uma esperança que se importa, que assume, que se despoja ao outro e se faz sensível com o que se aproxima e a toca: uma esperança responsável.

\section{Referências}

BAUMAN, Z. Modernidade líquida. Rio de Janeiro: Zahar, 2001.

BLOCH, E. O princípio esperança. Rio de Janeiro: Contraponto, 2005.

BOFF, C. O livro do sentido. Crise e busca de sentido hoje (parte crítica-analítica). São Paulo: Paulus, 2014.

CONCÍLIO VATICANO II. Constituição pastoral Gaudium et Spes [GS]. In: Mensagens, Discursos e Documentos. São Paulo: Paulinas, 1998.

FRANCISCO. Evangelii Gaudium [EG]. São Paulo: Paulus, Loyola, 2013.

GIDDENS, A. Modernidade e identidade. Rio de Janeiro: Zahar, 2002.

GUTIÉRREZ, G. Beber em seu próprio poço: itinerário espiritual de um povo. São Paulo: Loyola, 2000.

GUTIÉRREZ, G. Onde dormirão os pobres. 3. ed. São Paulo: Paulus, 2003.

JONAS, H. O princípio responsabilidade: ensaio de uma ética para a civilização tecnológica. Rio de Janeiro: Contraponto/PUC-Rio, 2006.

KUZMA, C. O futuro de Deus na missão da esperança: uma aproximação escatológica. São Paulo: Paulinas, 2014.

MOLTMANN, J. Teologia da esperança: estudo sobre os fundamentos e as consequências de uma escatologia cristã. São Paulo: Loyola/Teológica, 2005.

MOLTMANN, J. O Deus crucificado: a cruz de Cristo como base e crítica da teologia cristã. Santo André: Academia Cristã, 2011. 
MOLTMANN, J. La giustizia crea futuro: una politica ispirata alla pace e un'etica fondata sulla creazione in un mondo minacciato. Brescia: Queriniana, 1990.

MOLTMANN, J. Ética da esperança. Petrópolis: Vozes, 2012.

MOLTMANN, J. Weiter Raum. Eine Lebensgeschichte. München: Gütersloher Verlaghaus, 2006.

PANNENBERG, W. Teologia sistemática vol. III. Santo André: Academia Cristã, 2009. PIAZZA, O. F. A esperança: lógica do impossível. São Paulo: Paulinas, 2004.

RIBEIRO, H. Quem somos? De onde viemos? Para onde vamos? Antropologia teológica. Petrópolis: Vozes, 2007.

SOBRINO, J. Jesus o Libertador: história de Jesus de Nazaré. Petrópolis: Vozes, 1994. SOBRINO, J. A fé em Jesus Cristo: ensaio a partir das vítimas. Petrópolis: Vozes, 2000.

Recebido: 22/06/2018

Received: 06/22/2018

Aprovado: 30/07/2018 Approved: 07/30/2018 